\title{
Differences in functional and structural properties of segments of the rat tail artery
}

\author{
F.M. Souza1 ${ }^{1}$ A.S. Padilha1, I. Stefanon ${ }^{1}$ and D.V. Vassallo ${ }^{1,2}$ \\ ${ }^{1}$ Departamento de Ciências Fisiológicas, Universidade Federal do Espírito Santo, Vitória, ES, Brasil \\ ${ }^{2}$ Escola Superior de Ciências da Santa Casa de Misericórdia (EMESCAM), Vitória, ES, Brasil \\ Correspondence to: D.V. Vassallo, PPGCF/CBM/UFES, Av. Marechal Campos, 1468, Maruípe, \\ 29040-091 Vitória, ES, Brasil \\ Fax: +55-27-3335-7330. E-mail: daltonv2@terra.com.br
}

\begin{abstract}
The investigation of resistance vessels is generally costly and difficult to execute. The present study investigated the diameters and the vascular reactivity of different segments of the rat tail artery (base, middle, and tail end) of 30 male Wister rats (EPM strain) to characterize a conductance or resistance vessel, using a low-cost simple technique. The diameters (mean \pm SEM) of the base and middle segments were $471 \pm 4.97$ and $540 \pm 8.39 \mu \mathrm{m}$, respectively, the tail end was $253 \pm 2.58 \mu \mathrm{m}$. To test reactivity, the whole tail arteries or segments were perfused under constant flow and the reactivity to phenylephrine (PHE; $0.01-300 \mu \mathrm{g})$ was evaluated before and after removal of the endothelium or drug administration. The maximal response $\left(E_{\max }\right)$ and sensitivity $\left(\mathrm{pED}_{50}\right)$ to PHE of the whole tail and the base segment increased after endothelium removal or treatment with $100 \mu \mathrm{M}$ L-NAME, which suggests modulation by nitric oxide. Indomethacin $(10 \mu \mathrm{M})$ and tetraethylammonium $(5 \mathrm{mM})$ did not change the $E_{\max }$ or $\mathrm{pED}_{50}$ of these segments. PHE and L-NAME increased the $\mathrm{pED}_{50}$ of the middle and the tail end only and indomethacin did not change $\mathrm{pED}_{50}$ or $\mathrm{E}_{\max }$. Tetraethylammonium increased the sensitivity only at the tail end, which suggests a blockade of vasodilator release. Results indicate that the proximal segment of the tail artery possesses a diameter compatible with a conductance vessel, while the tail end has the diameter of a resistance vessel. In addition, the vascular reactivity to PHE in the proximal segment is nitric oxide-dependent, while the tail end is dependent on endothelium-derived hyperpolarizing factor.
\end{abstract}

Key words: Rat tail artery; Phenylephrine; Resistance artery; Endothelium; Conductance artery

Research supported by CAPES and CNPq.

Received June 20, 2007. Accepted April 15, 2008

\section{Introduction}

The rat tail artery has been used as a model to study several functional aspects of vascular smooth muscle (1$9)$. Some studies refer to the tail artery as a resistance artery (10-13); however, these studies do not define criteria for this classification. In fact, resistance vessels are arterioles and small arteries and 40 to $55 \%$ of the systemic vascular resistance resides in vessels with diameters $>100$ $\mu \mathrm{m}$ (14) up to a limit of $400 \mu \mathrm{m}$ (15).

Several studies have shown a significant difference in the vascular function between resistance and conductance arteries, and the techniques used to study the resistance vessels are costly due to the size of the vessel and to the high cost of the equipment for isometric or pressurized recordings. The tail artery is a suitable preparation for analysis of pressor reactivity and the perfusion technique is significantly less expensive than the measurement of pressurized arteries or isometric recordings of the 4th branch of the mesenteric artery, which is usually considered to be a resistance artery. Although frequently used as an entire isolated vascular bed (5-9) or as a small isolated dissected segment for pressurized artery protocols $(2,10$ $13)$, the caliber of this artery changes as it reaches the tail end. There are no reports describing the characteristics of different segments of this artery.

In addition, previous studies have demonstrated that the main endothelial factor liberated by the tail vascular bed is nitric oxide (NO) (6-8). This relaxing factor is released mainly by the vascular endothelium of conduc- 
tance arteries (16-18). However, in resistance arteries, the main relaxing factor released by endothelium is the endothelium-derived hyperpolarizing factor (EDHF) (1923).

Therefore, the present study evaluated and compared three characteristic: 1) the caliber of the base, middle and tail end segments of the tail artery; 2) the pressor responses of these segments during continuous infusion of different concentrations of phenylephrine (PHE); 3) the endothelial modulation of the vascular tone of these segments. These experiments were used to validate the perfusion of these preparations as a method to investigate vascular reactivity and to define whether the tail end of the tail artery might have characteristics similar to those described for a resistance artery.

\section{Material and Methods}

Rat tail arteries obtained from 30 male Wistar rats (EPM strain) weighing 250-350 g were used in this study. All experiments were conducted in compliance with the guidelines for biomedical research as stated by the Brazilian Societies of Experimental Biology. All rats had free access to water and were fed rat chow ad libitum. Five to 10 rats were used for each experimental group.

Isolated rat tail vascular beds were used as previously reported (24). In short, the rats were anesthetized intraperitoneally (ip) with $65 \mathrm{mg} / \mathrm{kg}$ sodium pentobarbital, and after the loss of the righting reflex, $500 \mathrm{IU}$ heparin (ip) was administered. Ten minutes after the administration of heparin, a 1-cm strip of the tail artery was dissected free and cannulated with an intracath (Nipro 24G $3 \frac{3}{4}$, Sorocaba, SP, Brazil) near the base of the tail.

The tail artery was then cannulated and perfused, either entirely or divided into 3 segments. Preparations were divided into 4 groups according to the place of the cannulation: whole tail group $(\mathrm{N}=12)$, base group $(\mathrm{N}=7)$, middle group $(\mathrm{N}=6)$, and tail end group $(\mathrm{N}=5)$.

The vascular bed was flushed with Krebs-Henseleit buffer (KHB: $120 \mathrm{mM} \mathrm{NaCl}, 5.4 \mathrm{mM} \mathrm{KCl}, 1.2 \mathrm{mM} \mathrm{MgCl}_{2}$, $1.25 \mathrm{mM} \mathrm{CaCl}_{2}, 2.0 \mathrm{mM} \mathrm{NaH}_{2} \mathrm{PO}_{4}, 27 \mathrm{mM} \mathrm{NaHCO}_{3}, 11 \mathrm{mM}$ glucose, and $30 \mu \mathrm{M}$ EDTA) bubbled with $5 \% \mathrm{CO}_{2}-95 \% \mathrm{O}_{2}$, at $36 \pm 0.5^{\circ} \mathrm{C}$. The tail was then severed from the body and placed in a tissue bath and perfused with $\mathrm{KHB}$ at a constant flow of $2.5 \mathrm{~mL} / \mathrm{min}$ with a peristaltic pump (Milan, Colombo, PR, Brazil). After a 30- to 45-min equilibration period, the experimental protocol was initiated. Mean perfusion pressure was measured using a pressure transducer (TPS-2, InCor, São Paulo, SP, Brazil) and the data recorded using an interface and software for computer data acquisition (model MP100A, BIOPAC Systems, Inc.,
Santa Barbara, CA, USA) with a sample rate of $500 \mathrm{~Hz}$ per channel. Because a constant flow was used, changes in the perfusion pressure reflected changes in vascular resistance.

Randomized doses of PHE (0.01, 0.03, 0.1, 0.3, 1, 3, $10,30,100$, and $300 \mu \mathrm{g}$, in bolus, in $100 \mu \mathrm{L}$; Sigma, USA) were injected into the rubber tubing just before the pump and the pressor effect was measured. A period of 7 to 10 min was allowed between consecutive doses of PHE that were constantly injected following the return of perfusion pressure to basal values.

\section{Experimental protocol}

Four protocols were used. In the first protocol after a 30- to 45-min stabilization period, endothelial integrity was evaluated with acetylcholine (ACh) administration (5 $\mu \mathrm{g}$ in $100 \mu \mathrm{L})$ in the tail artery pre-contracted with PHE (100 nM). Endothelial integrity was considered adequate when relaxation was greater than $50 \%$. Relaxation to $\mathrm{ACh}$ reached $55.7 \pm 1.6 \%$ in all groups. Smooth muscle viability was determined using sodium nitroprusside (SNP; $0.1 \mathrm{mg} / \mathrm{mL}$ ) into the tail artery previously contracted with PHE. All groups showed a relaxation of $56.9 \pm 1.6 \%$.

Subsequently, increasing doses of PHE (0.01-300 $\mu \mathrm{g}$, as bolus injections of $100 \mu \mathrm{L}$ ) were administered into the infusion medium in arteries with intact endothelium (CT). The same protocol, as described above, was performed in the same preparations following endothelial damage by a bolus injection of $8 \mathrm{mg}$ CHAPS \{3-[(3-chloroamidopropyl) dimethylammonio]-1-propane-sulfonate $\}$ in $80 \mu \mathrm{L}$ as previously described (6). The absence of functional endothelium (E-) was confirmed by the inability of ACh $(5 \mu \mathrm{g}$ in 100 $\mu \mathrm{L})$ to produce relaxation. The endothelium-independent vasodilator response to $0.1 \mathrm{mg} / \mathrm{mL}$ SNP was also determined. Responses to PHE were measured 30 min after endothelial damage.

In order to determine the involvement of $\mathrm{NO}$ and of the prostanoids derived from the cyclooxygenase pathway on the pressure response to PHE, preparations were perfused for 60 min with $100 \mu \mathrm{M}$ L-NAME, the NO synthase inhibitor ( $N=5$ to 7$)$, or $10 \mu \mathrm{M}$ indomethacin $(\mathrm{N}=6)$, respectively. Basal NO release was evaluated by comparing the areas under the dose-response curves for PHE obtained in the absence and presence of L-NAME (7). The same analysis was performed evaluating dose-response curves to PHE during perfusion of KHB solution with indomethacin.

To evaluate the activity of a $\mathrm{K}^{+}$-channel opener, pressor responses to PHE were determined in the absence and in the presence of $5 \mathrm{mM}$ tetraethylammonium (TEA) after a 30-min equilibration period. 
Analysis of the diameters of the tail artery segments

After the experiments, the segments of the tail artery were dissected, flushed with and fixed in Bouin solution for $12 \mathrm{~h}$. After standard histological processing and embedding in paraffin, $5-\mu \mathrm{m}$ thick serial sections were prepared for hematoxylin/eosin staining. For each tail segment, 4 transversal sections were used separated by a $40-\mu \mathrm{m}$ interval. The vessel diameter was measured with a micrometer scale and a 100X immersion objective.

\section{Data analysis}

Results of perfusion pressure measurements are reported as changes in the mean perfusion pressure by subtracting peak pressure from baseline pressure.

For each dose-response curve for PHE, the maximum effect $\left(E_{\max }\right)$ and the bolus dose $(\mu \mathrm{g})$ that produced onehalf $E_{\max }\left(-\log E D_{50}\right)$ were estimated using non-linear regression analyses (GraphPad Prism Software, San Diego, CA, USA). The sensitivity of the agonists is reported as $\mathrm{pED}_{50}\left(-\log E \mathrm{D}_{50}\right)$.

Data are reported as mean \pm SEM. Data were analyzed using a $t$-test and one-way ANOVA. When ANOVA showed a significant treatment effect, a post hoc Tukey test was used to compare means. $\mathrm{P}<0.05$ was considered to be significant.

\section{Results}

Relaxation with $5 \mu \mathrm{g}$ ACh in arteries previously contracted with $10 \mathrm{nM}$ PHE did not differ in the studied segments. Similarly there were no differences in the relaxation to SNP in the 3 arterial segments, or in the whole tail (Table 1).

PHE increased the perfusion pressure of the tail artery of the rat in the 4 groups studied dose-dependently but no differences between $E_{\max }$ or $p E D_{50}$ values were observed (Table 1).

Time control experiments were conducted to deter- mine whether the duration of the experiment and the performance of the first dose-response curve to PHE could influence the stability of the preparations. No changes in baseline pressure or pressure responses to PHE were observed in the 4 groups studied (data not shown).

To investigate the role of the endothelium in the whole tail and the 3 segments of the tail, PHE dose-response curves were performed before and after endothelial damage (Table 1). Endothelial damage was confirmed by the absence of the relaxation response to ACh (data not shown) and the baseline perfusion pressure increased in all groups. Endothelial-independent relaxation produced by SNP was not affected by endothelial damage.

Figure 1 and Table 2 show that the sensitivity to PHE increased after endothelial damage but the $E_{\max }$ only increased for the whole tail and the base of the tail. $E_{\max }$ did not increase in the middle segment or at the end of the tail artery.

To determine the role of endothelial-derived factors, the involvement of the arachidonic acid and cyclooxygenase pathway was investigated using indomethacin, a well-known cyclooxygenase inhibitor. Baseline perfusion pressure and the dose-response curve parameters, $E_{\max }$ and $\mathrm{pED}_{50}$, did not change after indomethacin treatment (Figure 2) showing that the arachidonic acid-cyclooxygenase pathway does not play a role in the pressure response to PHE. The participation of $\mathrm{NO}$ in the different segments of the tail artery was investigated with $100 \mu \mathrm{M} \mathrm{L}$ NAME, a non-selective inhibitor of NO synthase. Baseline perfusion pressure was not affected. Regarding the doseresponse curves to $\mathrm{PHE}$, L-NAME increased $\mathrm{E}_{\max }$ and $p E D_{50}$ in the whole tail and in the base segment. However, the middle and tail end segments did not have changes in $\mathrm{E}_{\max }$ or in $\mathrm{pED}_{50}$ (Figure 3 and Table 3 ).

Because systemic vascular resistance resides in vessels with diameters $>100 \mu \mathrm{m}(14)$ up to a limit of 400 $\mu \mathrm{m}(15)$, we measured the diameter of the three different portions of the tail artery. The diameters (mean \pm SEM

Table 1. Pharmacological properties of segments of the rat tail artery.

\begin{tabular}{llllllc}
\hline & ACh (\%) & SNP $(\%)$ & $E_{\max }(\mathrm{mmHg})$ & $\mathrm{pED} 50$ & MPP before $(\mathrm{mmHg})$ & MPP after $(\mathrm{mmHg})$ \\
\hline Entire tail & $52.9 \pm 6.8$ & $65.3 \pm 4.2$ & $306.5 \pm 27.7$ & $2.6 \pm 0.2$ & $80.8 \pm 4.0$ & $133.0 \pm 13.3^{*}$ \\
Base & $49.8 \pm 2.8$ & $62.2 \pm 2.5$ & $304.8 \pm 8.2$ & $2.3 \pm 0.09$ & $46.8 \pm 5.0$ & $72.3 \pm 3.9^{*}$ \\
Middle & $58.3 \pm 5.2$ & $70.0 \pm 5.2$ & $421.2 \pm 67.5$ & $2.2 \pm 0.1$ & $55.6 \pm 6.4$ & $88.4 \pm 14.4^{*}$ \\
Tail end & $59.0 \pm 5.2$ & $69.7 \pm 3.2$ & $355.7 \pm 39.8$ & $2.8 \pm 0.1$ & $55.9 \pm 7.6$ & $92.1 \pm 10.7^{*}$
\end{tabular}

Data are reported as mean \pm SEM for 5-7 experiments. $\mathrm{ACh}=$ relaxation to acetylcholine; $\mathrm{SNP}=$ relaxation to sodium nitroprusside; $\mathrm{E}_{\max }=$ maximal response to phenylephrine; $\mathrm{pED}_{50}=$ sensitivity to phenylephrine under control conditions; MPP = mean perfusion pressure before and after endothelial damage with CHAPS. pED 50 values are -log $E D_{50}$.

${ }^{*} \mathrm{P}<0.05$ (paired $t$-test). 
A

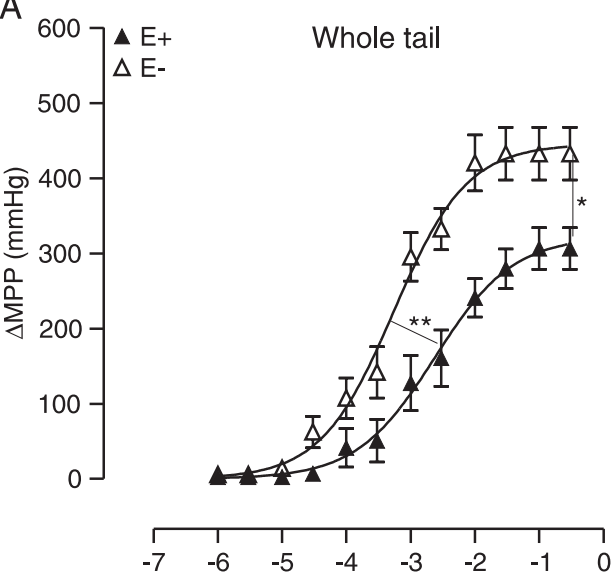

C

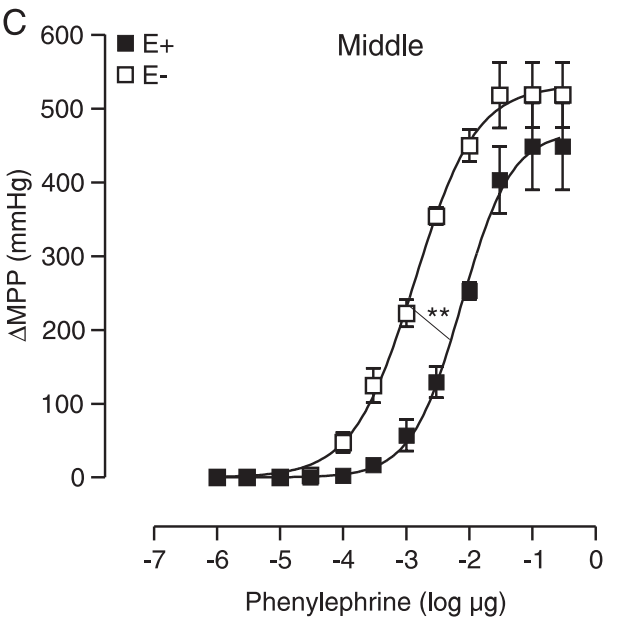

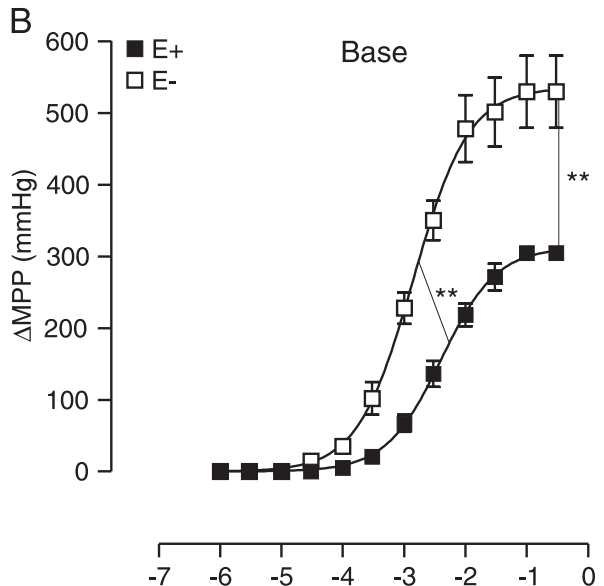

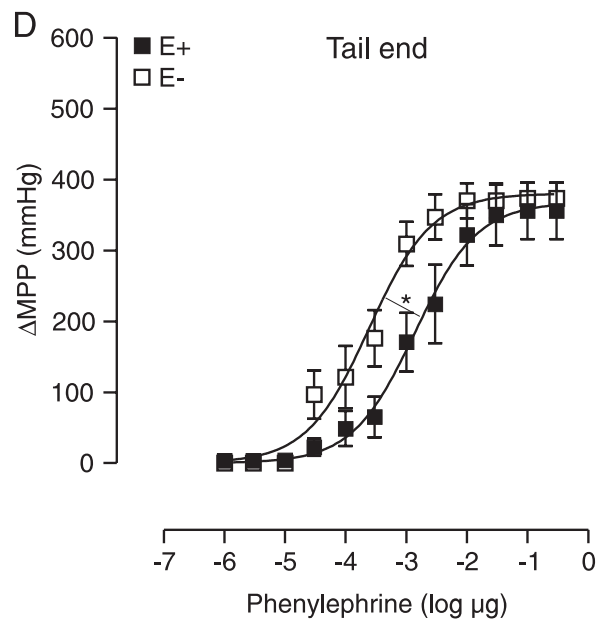

Figure 1. Changes of the mean perfusion pressure $(\triangle \mathrm{MPP} ; \mathrm{mmHg})$ produced by increasing doses of phenylephrine in the whole tail $(A)$, base $(B)$, middle $(C)$, and end (D) of the vascular bed from Wistar rats. Dose-response curves were constructed in preparations with $(E+)$ and without $(E-)$ endothelium. Data are reported as means \pm SEM for 5-10 experiments. The line between the curves $E+$ and $\mathrm{E}$ - represents the difference in $\mathrm{pED} 50$ or $\mathrm{E}_{\max } \cdot{ }^{*} \mathrm{P}<0.05$ and ${ }^{* *} \mathrm{P}<0.01, \mathrm{E}+v s \mathrm{E}-, t$-test, repeated measures.

in $\mu \mathrm{m}$ for 5 tails) were base $=471 \pm 4.9$, middle $=540 \pm$ 8.39 , and tail end $=253 \pm 2.58$. The diameter of the tail end segment was significantly less than the other segments ( $P<0.05$, one-way randomized ANOVA). Only the tail end presented characteristics similar to those reported for resistance vessels, i.e., the diameter being $<400 \mu \mathrm{m}$.

Since vasodilation of resistance arteries is only slightly dependent on $\mathrm{NO}$ and the arachidonic acidcyclooxygenase pathway, the dependence on hyperpolarizing factors was studied using $5 \mathrm{mM}$ TEA. After a 5-mM TEA treatment, the sensitivity to pressor effects of PHE in the tail end increased without any change in $E_{\max }$ values (Figure 4). However, in the whole, base and middle tail, $5 \mathrm{mM}$ TEA did not affect the vascular reactivity to PHE (results not shown).
Table 2. Maximal response $\left(E_{\max }\right)$ and sensitivity $\left(p E D_{50}\right)$ to phenylephrine in the entire tail, base, middle and tail end with $(\mathrm{E}+)$ and without endothelium (E-) after damage with CHAPS.

\begin{tabular}{lll}
\hline & $\mathrm{E}_{\max }(\mathrm{mmHg})$ & \multicolumn{1}{c}{$\mathrm{pED}_{50}$} \\
\hline Entire tail E+ & $307 \pm 27.7$ & $2.7 \pm 0.2$ \\
Entire tail E- & $433 \pm 34.8$ & $3.3 \pm 0.1^{*}$ \\
Base E+ & $305 \pm 8.2$ & $2.4 \pm 0.09$ \\
Base E- & $530 \pm 50.3^{*}$ & $2.9 \pm 0.05^{*}$ \\
Middle E+ & $448 \pm 58.9$ & $2.2 \pm 0.1$ \\
Middle E- & $518 \pm 44.4$ & $2.9 \pm 0.1^{*}$ \\
Tail end E+ & $356 \pm 39.9$ & $2.8 \pm 0.2$ \\
Tail end E- & $373 \pm 22.1$ & $3.6 \pm 0.2^{*}$
\end{tabular}

Data are reported as mean \pm SEM for 5-7 experiments. DED $_{50}$ values are $-\log \mathrm{ED}_{50}$.

${ }^{*} \mathrm{P}<0.05$, E- compared to $\mathrm{E}+$ (paired $t$-test). 

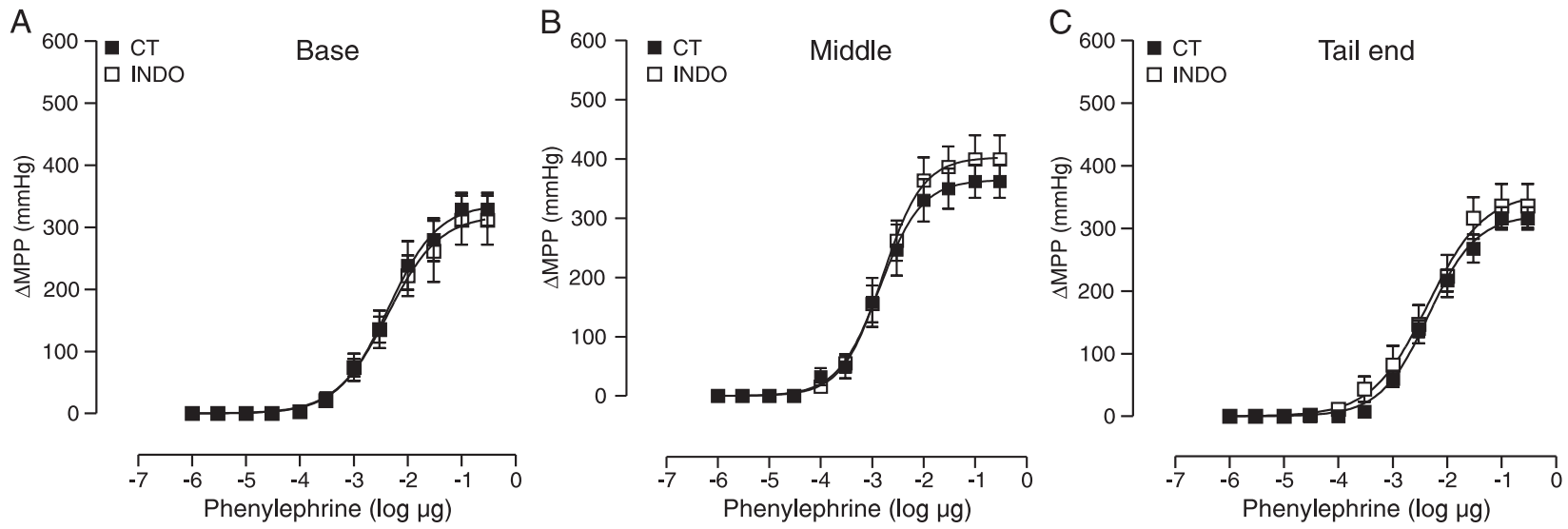

Figure 2. Changes of the mean perfusion pressure $(\triangle \mathrm{MPP} ; \mathrm{mmHg})$ produced by increasing doses of phenylephrine in the base (A), middle (B), and end (C) of the vascular bed from Wistar rats. Dose-response curves were constructed in preparations with intact endothelium before (CT) and 30 min after treatment with $10 \mu \mathrm{M}$ indomethacin (INDO). Data are reported as means \pm SEM for 5-7 experiments.
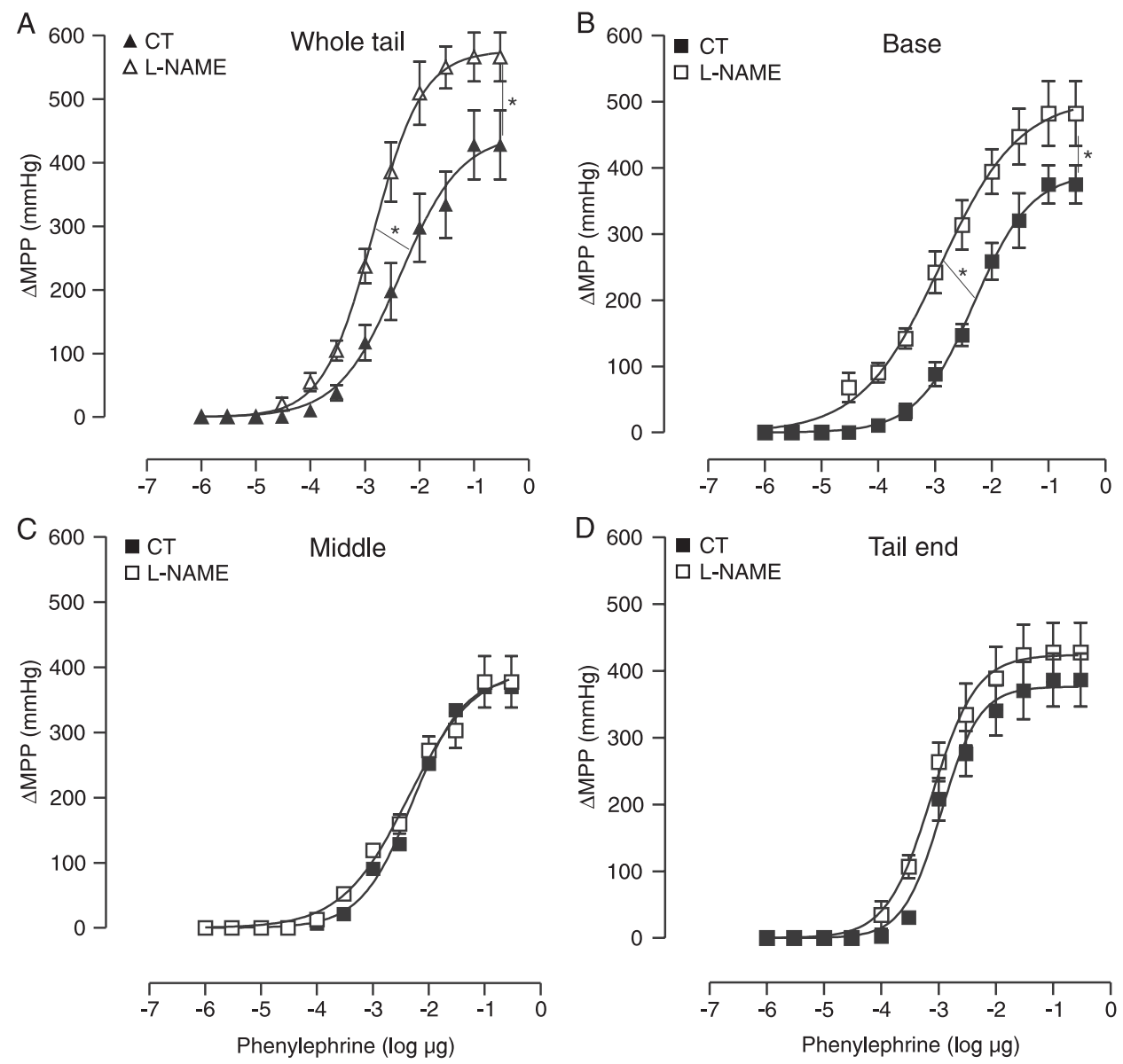

Figure 3. Changes of the mean perfusion pressure $(\triangle \mathrm{MPP} ; \mathrm{mmHg})$ produced by increasing doses of phenylephrine in the whole tail $(A)$, base $(B)$, middle $(C)$, and tail end $(D)$ of the vascular bed from Wistar rats. Dose-response curves were constructed in preparations with intact endothelium before (CT) and $30 \mathrm{~min}$ after treatment with $100 \mu \mathrm{M}$ L-NAME. Data are reported as means \pm SEM for 5-7 experiments. The line between the curves CT and L-NAME represents the difference in $\mathrm{pED}_{50}$ or $\mathrm{E}_{\max } \cdot{ }^{*} \mathrm{P}<0.05, \mathrm{CT} v s$ L-NAME, $t$-test, repeated measures. 
Table 3. Maximal response $\left(E_{\max }\right)$ and sensitivity $\left(p E_{50}\right)$ to phenylephrine in the entire tail, base, middle and tail end before and after perfusion for 30 min with L-NAME.

\begin{tabular}{lcl}
\hline & $\mathrm{E}_{\max }(\mathrm{mmHg})$ & $\mathrm{pED}_{50}$ \\
\hline Entire tail without L-NAME & $428 \pm 54.3$ & $2.3 \pm 0.2$ \\
Entire tail with L-NAME & $566 \pm 38.4$ & $2.8 \pm 0.08^{*}$ \\
Base without L-NAME & $375 \pm 28.8$ & $2.3 \pm 0.2$ \\
Base with L-NAME & $482 \pm 48.8^{*}$ & $3.0 \pm 0.1^{*}$ \\
Middle without L-NAME & $370 \pm 18.2$ & $2.3 \pm 0.08$ \\
Middle with L-NAME & $378 \pm 39.7$ & $2.4 \pm 0.1$ \\
Tail end without L-NAME & $400 \pm 48.2$ & $2.9 \pm 0.07$ \\
Tail end with L-NAME & $428 \pm 44.6$ & $3.1 \pm 0.1$
\end{tabular}

Data are reported as mean \pm SEM for $5-7$ experiments. $p E D_{50}$ values are $-\log E D_{50}$.

${ }^{*} \mathrm{P}<0.05$, with L-NAME compared to without L-NAME (paired $t$ test).

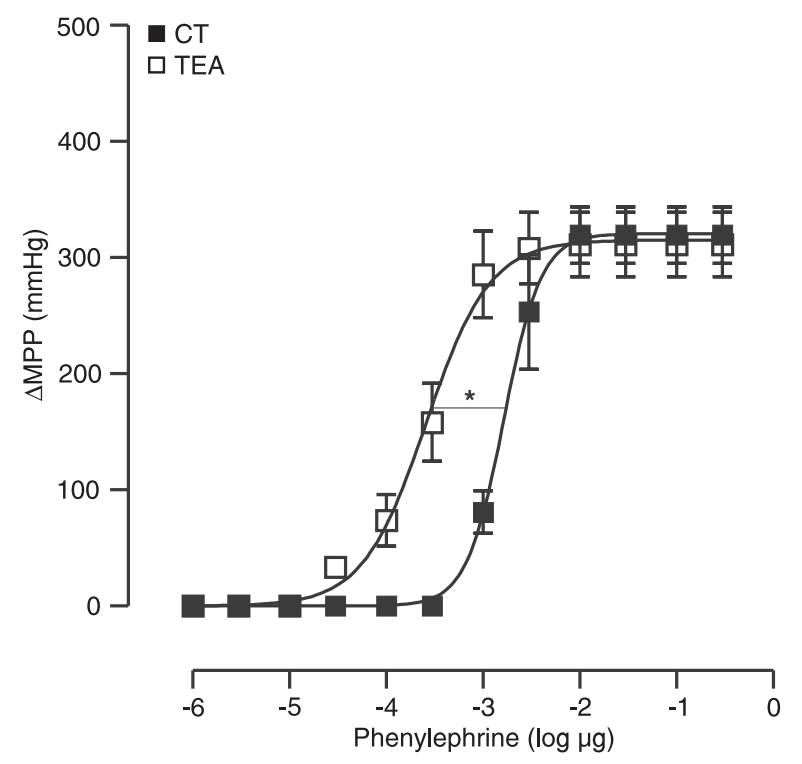

Figure 4. Changes of the mean perfusion pressure ( $\triangle \mathrm{MPP} ; \mathrm{mmHg})$ produced by increasing doses of phenylephrine in the tail end of the vascular bed from Wistar rats. Dose-response curves were constructed in preparations with intact endothelium before (CT) and after treatment with $5 \mathrm{mM}$ tetraethylammonium (TEA). Data are reported as means \pm SEM for 5-7 experiments. The horizontal line between the CT and TEA curves indicates the difference in pED 50 . ${ }^{*} P<0.01 \mathrm{CT}$ vs TEA, $t$-test, repeated measures.

\section{Discussion}

The results of the present study have shown that the proximal segment (base) of the tail artery of the rat possesses a diameter compatible with that reported for conductance arteries, while at the same time releasing NO. On the other hand, the distal segment of the tail artery possesses a diameter similar to a resistance artery, and its tone reduction depends on the release of EDHF.

The tail artery of the rat can be an important model for studying vascular function. Perfusion experiments enable the analysis of endothelial and smooth muscle tone regulation $(2-9,23)$ and the functional analysis of $\mathrm{Na}^{+}$-pump activity $(8,24)$. Previous studies were performed using the whole perfused tail artery or small isolated segments of this artery.

The rat tail artery develops a high perfusion pressure in response to $2.5 \mathrm{~mL} / \mathrm{min}$ flow when compared to other vascular beds $(24,25)$. The perfusion pressure increases as a function of flow and, as previously suggested (1-4), it is also suitable for the assay of vasopressor agents for isolated segments of arteries. These arteries respond to PHE stimulation with dose-dependent pressor responses. Therefore, as previously described, the rat tail artery develops an important intrinsic tone and a large vasopressor response to $\operatorname{PHE}(5,6,24)$ and has been reported to be a resistance vessel (10-13). Although frequently used as a proximal segment for perfusion $(2,3,10-13)$ or as a whole isolated vascular bed $(5,6,24)$, the diameter of this artery changes as it reaches the tail end and, to this date, there are no reports describing the characteristics of different segments of this artery.

Vessels with diameters $>100 \mu \mathrm{m}$ (14) up to a limit of $400 \mu \mathrm{m}$ (15) are considered to be arterioles and small arteries and are responsible for 40 to $55 \%$ of the systemic vascular resistance. The endothelial control of the vasodilator tone in these vessels is different from conductance vessels and EDHF and NO appear to be the main mechanisms that may account for this $(11,14,19-22)$.

Thus, we used the whole tail artery of the rat or its division into 3 segments for perfusion in vitro under constant flow, in order to both establish and compare their characteristics and, at the same time, to define whether the end segment of the tail artery might be considered to be a resistance artery, due to its diameter. The diameter at the initial segment of this artery was compatible with a conductance artery. These measurements are important because they determine which portion of the tail artery might be referred to as resistance or conductance artery.

As to the vascular reactivity to PHE, the four groups presented several common characteristics. The pressor response to PHE was similar without any changes in $E_{\max }$ or in the sensitivity to the vasoconstrictor action produced. When the endothelial-dependent and -independent relaxations were tested responses were also similar. Similarities among different vascular beds formed by conductance or other vessels were also shown (8). 
As previously reported for the whole tail arterial bed (6), no changes in baseline perfusion pressure were observed after performing the dose-response curve to PHE, which suggests that this procedure did not change the functional behavior of the tail artery.

However, after endothelial damage, the sensitivity increased in all groups, as expected, but $E_{\text {max }}$ increased only for the whole tail and the base segment. This finding suggests that the endothelium plays a different role for each arterial tail segment. The endothelial damage was confirmed by the lack of effect of ACh but the action of SNP was not affected, which seems to indicate that the smooth muscle cells were not damaged.

In order to determine which endothelial factor was involved in these different responses, the action of LNAME was investigated. For the whole tail and the base segment, $E_{\max }$ and the sensitivity to PHE increased, as it did after the endothelial lesion. This is a clear indication that $\mathrm{NO}$ is an important endothelial factor involved in vascular tone regulation in these vessels $(26,27)$. In addition, this behavior is often found in conductance arteries $(17,18,28)$. The middle and the end segments were not affected by L-NAME treatment. This suggests that these segments have a minor dependency on NO.

In order to investigate the role of prostanoids in the tail artery and in the 3 segments, the effects of indomethacin, a cyclooxygenase inhibitor, were evaluated. No changes were observed in the 3 groups, which suggest that prostanoids do not play an important role in vascular tone regulation in these vessels (22).

Finally, we tested the role of EDHF in the modulation of the pressor responses to PHE. For that we used TEA, a well-known $\mathrm{K}^{+}$-channel inhibitor. The results demonstrated that the pressor response to PHE was not modified by infusion of $5 \mathrm{mM}$ TEA in the proximal and middle segments, indicating that EDHF does not play a role in the regulation of vascular tone. However, in distal segments, TEA increased the sensitivity to PHE, suggesting that a hyperpolarizing factor was inhibited. These findings corroborate other studies that have demonstrated that in resistance arteries EDHF plays a key role in the regulation of vascular tone (19-21).

The results of this study suggest that the proximal segment of the tail artery possesses a diameter compatible with conductance vessels, while the tail end segment has characteristics in diameter and tone regulation similar to those of resistance vessels. This segment of the tail artery is a suitable resistance vessel preparation. The perfusion technique is very easy to perform and is less expensive than the analysis of pressurized arteries or the analysis of the rings of the 4th branch of the mesenteric artery, usually considered to be a resistance artery (28).

\section{References}

1. Nicholas TE. A perfused tail artery preparation from the rat. J Pharm Pharmacol 1969; 21: 826-832.

2. Longhurst PA, Rice PJ, Taylor DA, Fleming WW. Sensitivity of caudal arteries and the mesenteric vascular bed to norepinephrine in DOCA-salt hypertension. Hypertension 1988; 12: $133-142$.

3. Capdeville-Atkinson C, Oster L, Thorin-Trescases N, Robert $A$, Boutinet $S$, Atkinson J. Intracellular free $\mathrm{Ca}^{2+}$ and vasoconstriction determined simultaneously in the perfused rat tail artery. Am J Physiol 1993; 265: C1689-C1702.

4. Chen XL, Rembold CM. Phenylephrine contracts rat tail artery by one electromechanical and three pharmacomechanical mechanisms. Am J Physiol 1995; 268: H74-H81.

5. Vassallo DV, Songu-Mize E, Rossoni LV, Amaral SM. Effects of ouabain on vascular reactivity. Braz J Med Biol Res 1997; 30: 545-552.

6. Rossoni LV, Cunha V, França A, Vassallo DV. The influence of nanomolar ouabain on vascular pressor responses is modulated by the endothelium. J Cardiovasc Pharmacol 1999; 34: 887-892.

7. Rossoni LV, Salaices M, Miguel M, Briones AM, Barker LA, Vassallo DV, et al. Ouabain-induced hypertension is accompanied by increases in endothelial vasodilator factors.
Am J Physiol Heart Circ Physiol 2002; 283: H2110-H2118.

8. Rossoni LV, Salaices M, Marin J, Vassallo DV, Alonso MJ. Alterations in phenylephrine-induced contractions and the vascular expression of $\mathrm{Na}^{+}, \mathrm{K}^{+}$-ATPase in ouabain-induced hypertension. Br J Pharmacol 2002; 135: 771-781.

9. Padilha AS, Rossoni LV, Xavier FE, Vassallo DV. Ouabain at nanomolar concentration promotes synthesis and release of angiotensin II from the endothelium of the tail vascular bed of spontaneously hypertensive rats. J Cardiovasc Pharmacol 2004; 44: 372-380.

10. Fouda AK, Atkinson J. Sensitivity to noradrenaline and electrical stimulation decreases with age in the rat tail artery. Naunyn Schmiedebergs Arch Pharmacol 1986; 334: 37-39.

11. Thompson LE, Rinaldi GJ, Bohr DF. Decreased activity of the sodium-calcium exchanger in tail artery of stroke-prone spontaneously hypertensive rats. Blood Vessels 1990; 27: 197-201.

12. Seasholtz TM, Gurdal H, Wang HY, Cai G, Johnson MD, Friedman E. Heterologous desensitization of the rat tail artery contraction and inositol phosphate accumulation after in vitro exposure to phenylephrine is mediated by decreased levels of Galphaq and Galphai. J Pharmacol Exp Ther 1997; 283: 925-931. 
13. Machkov VV, Tarasova OS, Timin EN, Rodionov IM. Effect of noradrenaline on tail arteries of SHR and WKY under perfusion at constant flow and constant pressure. Acta Physiol Scand 1997; 161: 41-46.

14. Pohl $U$, De Wit $C$, Gloe T. Large arterioles in the control of blood flow: role of endothelium-dependent dilation. Acta Physiol Scand 2000; 168: 505-510.

15. Christensen KL, Mulvany MJ. Location of resistance arteries. J Vasc Res 2001; 38: 1-12.

16. Ignarro LJ, Buga GM, Wood KS, Byrns RE, Chaudhuri G. Endothelium-derived relaxing factor produced and released from artery and vein is nitric oxide. Proc Natl Acad Sci U S A 1987; 84: 9265-9269.

17. Chataigneau T, Feletou M, Huang PL, Fishman MC, Duhault $\mathrm{J}$, Vanhoutte PM. Acetylcholine-induced relaxation in blood vessels from endothelial nitric oxide synthase knockout mice. Br J Pharmacol 1999; 126: 219-226.

18. Akimoto $Y$, Horinouchi $T$, Shibano $M$, Matsushita $M$, Yamashita $\mathrm{Y}$, Okamoto $\mathrm{T}$, et al. Nitric oxide (NO) primarily accounts for endothelium-dependent component of betaadrenoceptor-activated smooth muscle relaxation of mouse aorta in response to isoprenaline. J Smooth Muscle Res 2002; 38: 87-99.

19. Shimokawa H, Yasutake H, Fujii K, Owada MK, Nakaike R, Fukumoto $\mathrm{Y}$, et al. The importance of the hyperpolarizing mechanism increases as the vessel size decreases in endothelium-dependent relaxations in rat mesenteric circulation. J Cardiovasc Pharmacol 1996; 28: 703-711.

20. Brandes RP, Schmitz-Winnenthal FH, Feletou M, Godecke A, Huang PL, Vanhoutte PM, et al. An endothelium-derived hyperpolarizing factor distinct from $\mathrm{NO}$ and prostacyclin is a major endothelium-dependent vasodilator in resistance vessels of wild-type and endothelial NO synthase knockout mice. Proc Natl Acad Sci U S A 2000; 97: 9747-9752.

21. Hilgers $\mathrm{RH}$, Todd J Jr, Webb RC. Regional heterogeneity in acetylcholine-induced relaxation in rat vascular bed: role of calcium-activated $\mathrm{K}^{+}$channels. Am J Physiol Heart Circ Physiol 2006; 291: H216-H222.

22. Hoepfl B, Rodenwaldt B, Pohl U, De Wit C. EDHF, but not NO or prostaglandins, is critical to evoke a conducted dilation upon ACh in hamster arterioles. Am J Physiol Heart Circ Physiol 2002; 283: H996-H1004.

23. Tanko LB, Matrougui K. Can we apply results from large to small arteries? Circ Res 2002; 90: e68.

24. Franca AS, Rossoni LV, Amaral SM, Vassallo DV. Reactivity of the isolated perfused rat tail vascular bed. Braz J Med Biol Res 1997; 30: 891-895.

25. Vasquez EC, Bissoli NS, Moyses MR, Cabral AM. Contractile reactivity of the perfused mesenteric vascular bed from sinoaortic denervated rats to norepinephrine, methoxamine and verapamil. Braz J Med Biol Res 1988; 21: 629-632.

26. Vanhoutte PM, Rubanyi GM, Miller VM, Houston DS. Modulation of vascular smooth muscle contraction by the endothelium. Annu Rev Physiol 1986; 48: 307-320.

27. Moncada S, Palmer RM, Higgs EA. Nitric oxide: physiology, pathophysiology, and pharmacology. Pharmacol Rev 1991; 43: $109-142$

28. Mulvany MJ, Aalkjaer C. Structure and function of small arteries. Physiol Rev 1990; 70: 921-961. 